\title{
The Moral and Fiscal Implications of Antiretroviral Therapies for HIV in Africa
}

\author{
By Paul Collier ${ }^{\mathrm{a}}$ and Olivier Sterck ${ }^{\mathrm{b}}$
}

${ }^{a}$ Blavatnik School of Government, Oxford University, and the International Growth Centre; email: paul.collier@economics.ox.ac.uk

${ }^{\mathrm{b}}$ Oxford Department of International Development, Oxford University

\section{Abstract}

Thanks to antiretroviral therapies, people living with HIV can now have a near-normal life at a cost of a few hundred dollars per year. We postulate that given this newly low cost of maintaining lives, there is a moral duty to rescue those who are infected. This obligation creates a financial quasi-liability which for some African countries is comparable to their debt-to-GDP ratios. We construct a model to show that expenditure on prevention can pre-empt some of these liabilities. However, even with optimal prevention the quasi-liability is likely to remain too high to be affordable for a significant number of African countries. Extending the model to two players, we show that if the international community accepts part of the quasi-liability, as it does, it should finance a broadly equal share of prevention and treatment of future infections to mitigate moral hazard and avoid sub-optimal investment in prevention.

JEL codes: $\mathrm{I15}$, I18, E61, O11 


\section{Introduction}

Thanks to antiretroviral therapies, people living with HIV in developing countries can now have a near-normal life at a cost of a few hundred dollars per year. Reflecting this perception that the medical battle against AIDS is now winnable, a cover story of The Economist was entitled 'The End of AIDS?' "That this should be the title of a journal focused on economics was, however, ironic. In this paper we show that as HIV is becoming less of a medical calamity, a corollary is that it is becoming a major new fiscal liability, and one that is currently insufficiently recognized.

The existence of affordable treatment has changed the ethics of treatment. In Section 2 we introduce and explore how the concept of the moral duty to rescue might apply to the provision of ART to people living with HIV (PLHIV). We are concerned to base this duty firmly within widely accepted moral norms rather than to advocate for some ethical ideal. We then explore how the recognition of a moral duty to rescue has implications for the future financial liabilities of governments. While our focus is HIV in low-income countries, analogous interactions between ethical obligations and fiscal burdens will become significant in the OECD as costly new treatments continue to change cancer from a fatal to a chronic condition.

The long-term liability of HIV can be estimated by establishing the present and future stocks of people who are HIV+ and will therefore at some stage need ART to stay alive. In Section 2, we show that if this is recognized as a moral obligation, for some African countries the quasi-debt would be very substantial: the success of ART in reducing the threat to lives implies a large and growing threat to public finance. Section 3 makes the key step in the paper. While the moral duty to rescue requires expenditure on treatment, which can be conceptualized as a debt liability, expenditure on prevention can reduce this burden. For a state faced with long-term obligations arising from HIV, efficient resource allocation would therefore involve spending on prevention up to the point at which the marginal dollar reduces the discounted liability of treatment by at least one dollar. As such, prevention expenditures can be considered as an investment. In Section 4 we consider the appropriate apportionment of long-term spending for HIV between African governments and the international community, studying who should bear the cost and the responsibility of investment in prevention. In Section 5 we illustrate the optimal allocation of budgeting between treatment and prevention over time in the case of Malawi. Using circumcision as an example of a viable prevention strategy, we show that the extension of coverage would be a cost-effective way of reducing the fiscal burden of the moral duty to rescue.

Our study contributes to the limited academic literature on the political economy of HIV/AIDS. Most of the macroeconomic literature on HIV/AIDS studies the determinants of HIV incidence and prevalence (e.g. Kremer, 1996; Oster, 2005, 2012; Pongou and Serrano, 2013; Burke et al. 2014; Sterck, 2016) as well as the macroeconomic and demographic consequences of the epidemics (e.g. Haacker, 2004; Young, 2005; Fortson, 2011; Kalemli-Ozcan, 2012). Recent

\footnotetext{
${ }^{1}$ June $2^{\text {nd }}, 2011$.
} 
contributions in the global health literature have estimated the long-run cost of the fight against HIV by combining epidemiological and economic modelling (e.g. Over, 2012; Lule and Haacker, 2011). In the wake of antiretroviral therapies expansion, a few scholars have recently estimated the financial capacity of countries to pay for their HIV programs (e.g. Galárraga et al., 2013; Resch et al., 2015, Remme et al., 2016). There is a general agreement that the cost of scaling-up antiretroviral treatment and prevention is too high for those countries which are both highprevalence and very poor. In effect, in these societies the opportunity cost of public funds is too high for ART to have generated a widely shared recognition of a duty of rescue towards those who are HIV+. Yet that duty has been widely recognized among OECD populations with their much higher income levels, implying that the international community will have to co-fund for the foreseeable future. Despite this, there is essentially no academic literature on the scale and implications of future co-funding. International funding of ART programs potentially creates an acute moral hazard in which governments underfund prevention. We derive optimal expenditure on prevention and show how the problem of moral hazard might be addressed.

\section{The Moral Duty to Rescue and its long-run cost \\ 2.1. The moral duty to rescue and its qualifications}

Our starting point is the assumption that if with near certainty an early death of an identifiable individual can be averted and replaced by a healthy life at the cost of a few hundred dollars per person per year, most people would accept that at 21st Century global living standards there is a moral duty to rescue at the global, institutional level ${ }^{2}$. Supposing that the policies of democratic governments come to reflect the views of their citizens, our objective is to study the implications of this moral duty to rescue for the new economics of HIV. ${ }^{3}$ The moral duty to rescue identifiable people who are facing death need not imply that people recognize a broader obligation to help people poorer than themselves. This duty of rescue is ethically less demanding than radical frameworks such as Utilitarian Universalism. In Utilitarian ethics, the overarching objective is the maximization of global utility and from such an obligation a myriad of redistributive actions would follow (see e.g. Mankiw, and Weinzierl, 2010). As shown by Jonathan Haidt (2012), only a tiny minority of the global population subscribes to such ethics. In contrast, the duty to rescue is widely accepted as a moral responsibility, the classic example being that of a bystander to pull a drowning child out of a pond. Utilitarian Universalism might imply an obligation to build a fence around the pond to protect children from parental negligence. The important difference between the duty of

\footnotetext{
${ }^{2}$ By using the terminology "moral duty to rescue", we want to distance ourselves from the legal concept of the "duty to rescue" and the much-debated "rule of rescue" in ethics. The moral duty to rescue advocated in this paper is close to the institutional duty of rescue discussed in Rulli and Millum (2014).

3 The International Covenant on Economic Social and Cultural Rights (1966), the 2006 and 2011 Political Declaration of the UN committing to moving towards universal access to HIV prevention, treatment and care, the Millennium Development Goal 6, the 90-90-90 target of UNAIDS, the actions of PEPFAR and the Global Fund to Fight AIDS, Tuberculosis and Malaria and the generalization of ART access in Africa are, among others, elements showing that the provision of ART to people living with HIV is widely regarded as a moral imperative by governments and their population. More generally, there is a global consensus that developed countries have a moral responsibility to work to reduce hunger, severe poverty and health problems affecting poor countries (Council on Foreign Relations, 2012).
} 
rescue and such preventative actions is captured by the moral force of the statement 'this child will die unless you do $\mathrm{X}$ ' relative to 'there is a one-in-ten chance that each of ten unknown children will die unless you do $X$ '. As Pinker shows in his analysis of how moral language is used, moral force is only generated by a specific line of responsibility between $\mathrm{X}$ and the certain effect on an identifiable person (Pinker, 2007).

The moral duty to rescue is contingent (Rulli, T., and Millum, J., 2014). For example, if the pond has a lifeguard, he has the primary responsibility. Similarly, inability to swim might mitigate the obligation of the bystander. Analogously the duty to rescue those HIV+ falls primarily on the government, but only if it is affordable. In high-prevalence poor countries governments are unable to meet the cost of ART without making sacrifices that OECD societies recognise as unreasonable. Richer societies thereby become responsible. The revealed behaviour of OECD politicians suggests that in rich societies this duty is widely recognised: per capita GDP is over 70 times the cost of a year of life enabled. The relationship between income, health needs and responsibility is explored in Sterck et al. (2017).

Some other health conditions also generate a moral duty of rescue. Left untreated they are certain to cause catastrophic consequences, while treatment is neither so expensive as to pose an unreasonable burden, nor so cheap that recipients can be expected to pay for it, type-1 diabetes, tuberculosis and birth complications being examples. Nevertheless, HIV is distinctive. An efficient response against HIV requires an optimal mix of prevention and treatment. Prevention can be valued as an investment to reduce the treatment cost of future infections. Treatment itself has a preventative effect thereby generating positive spillovers in the long run. The complementarity between treatment and prevention will be analysed in section 4 .

Further, while the treatments of many diseases require a short run, early intervention, ARV treatment must continue through the lifetime of the recipient. ${ }^{4}$ In this sense, ART is similar to the treatment of chronic illnesses. This long duration is morally significant. Once treatment has commenced the moral case for continuing it is far stronger than the case for starting it. To discontinue a program of treatment intended to be permanent would take a specific decision which would be directly responsible for the death of a specific person: A's decision to withhold treatment would inflict certain and avoidable death on B, meeting the criteria for murder. Hence, acceptance of the moral duty to rescue locks future decision takers into a commitment to continue treatment: it is morally irreversible. Further, once general provision of treatment has begun, it would be morally and politically odious to introduce restrictions upon access. Unlike other public services, the consequence of exclusion is highly discontinuous. People who had an expectation of continued life must be told that they will be left to die whilst the service will continue to be provided to others.

4 This is also true for types- 1 diabetes. 
The implication of irreversibility is that the decision to introduce treatment generates a stream of future costs. It is therefore important that the decision be well informed as to these costs. In this sense it is analogous to sovereign borrowing and the resulting long term obligations to service the debt (Haacker, 2011; Lule and Haacker, 2011): the people currently in charge of policy take on obligations that must be met by citizens far into the future. Hence, it is helpful to reformulate the ART decision in terms of the stock of liabilities rather than current expenditures. This feature makes the application of the moral duty of rescue to HIV unique.

\subsection{From Flows of Costs to Stocks of Liabilities}

In Table 1, we estimate the long-term financial liability resulting from the moral duty to rescue for eight African countries which account for 45 per cent of the global HIV burden. ${ }^{5}$ In order to model the epidemic we use the SPECTRUM software (Futures Institute, 2014). SPECTRUM is a widely used modelling tool developed to support policy decisions concerning public health. It includes modules for HIV projections used by the UNAIDS secretariat to compiles estimates of HIV prevalence and incidence.

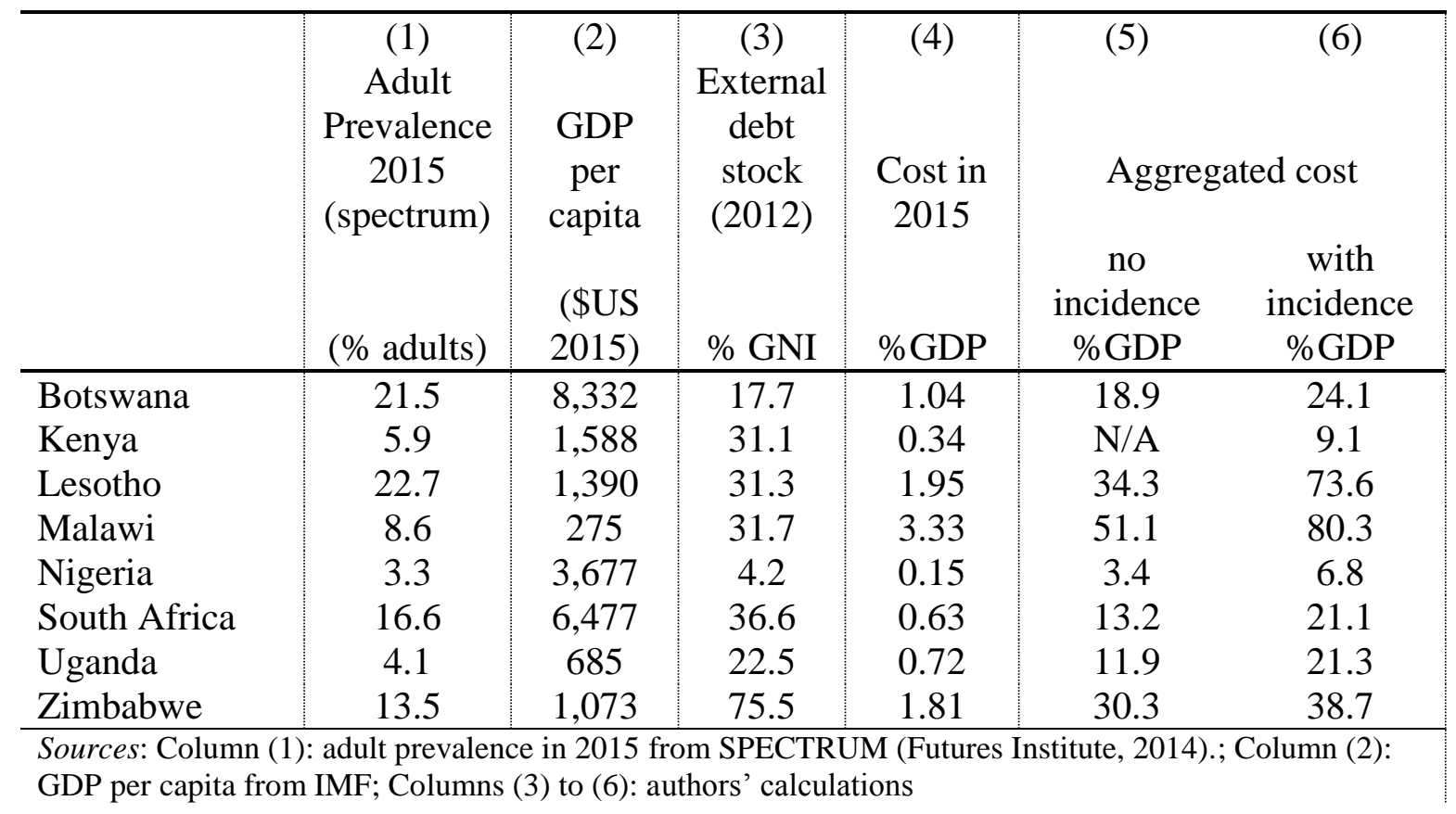

Table 1: Financial Implications of Long-term ART: the Moral duty to rescue as a Quasi-Debt

\footnotetext{
${ }^{5}$ Other scholars - chiefly Lule and Haacker (2011) and Atun et al. (2016) - estimated the fiscal cost of the HIV/AIDS quasi-liability. Because these studies are not anchored in a moral duty to rescue framework, their estimates rely on different assumptions. Notably, they assume lower discount rates, they include the cost of prevention, and they assume different coverage rates. Despite these differences, estimates of the cost of the HIV/AIDS quasi-liability are large and of the same order of magnitude.
} 
No ART program can realistically expect complete coverage of HIV positive individuals. UNAIDS has goals for the two components of coverage: diagnosis and treatment. Specifically, "90 per cent of all people living with HIV will know their HIV status" and "90 per cent of all people with diagnosed HIV infection will receive sustained antiretroviral therapy in 2020" (UNAIDS, 2014). These goals implicitly constitute a judgment as to what ART coverage the moral duty to rescue might reasonably require, namely 81 per cent of the eligible population. Our simulations therefore assume $81 \%$ ART coverage for eligible people. Eligibility for ART is usually defined in terms of CD4 count. ${ }^{6}$ Because the CD4 count is a continuous variable, and because ART achieves both treatment and prevention, any threshold determining when ART is justified for the purpose of prevention and when the moral duty to rescue kicks in is necessarily arbitrary. However, for estimation and policy purposes some threshold must be specified. As shown on Table 2, the median life expectancy of an HIV-positive adult between 25 and 34 years old who is not taking ART is expected to be 2.6 years when the CD4 drops below 200 cells $/ \mathrm{mm}^{3}$. This rises to 4.4 years when the threshold is set below 350 cells $/ \mathrm{mm}^{3}$ and 7.7 years when set below 500 cells $/ \mathrm{mm}^{3}$. To select which of these thresholds generates a moral duty to rescue, we follow the approach conventional for such issues of medical ethics, namely the Bolam test, whereby if a standard is widely practiced by qualified professionals it is deemed to be reasonable. Currently, the 350 cell threshold best meets this condition. The 500 cell threshold now encouraged by the WHO is not yet widely practised (Munthali et al. 2014), and an important part of its rationale is prevention, not rescue. For example, in their report justifying the switch from the $350 \mathrm{CD} 4 / \mathrm{mm}^{3}$ to $500 \mathrm{CD} 4 / \mathrm{mm}^{3}$, the WHO writes: "Expanding the eligibility criteria for ART and the options for using ARV drugs creates opportunities to save lives and reduce HIV transmission" (World Health Organization, 2013). Another reason for choosing the lower 350 cells $/ \mathrm{mm}^{3}$ is to avoid inflating our estimates.. We will show that even with the lower 350 cells $/ \mathrm{mm}^{3}$ the cost of treatment is macro-significant. However, recognizing the arbitrariness of this choice, in Figure 3 and Appendix 2 we show how estimates vary when the CD4 count threshold is increased.

\begin{tabular}{lcc} 
& $\begin{array}{c}\text { Median survival } \\
\text { time without ART }\end{array}$ & $\begin{array}{c}\text { Median survival } \\
\text { time without ART }\end{array}$ \\
\hline Age at infection & $15-24$ & $25-34$ \\
\hline \hline CD4 count & & \\
$>500$ & 16 & 12 \\
$350-500$ & 11.1 & 7.7 \\
$250-349$ & 7.5 & 4.4 \\
$200-249$ & 5 & 2.6 \\
$100-199$ & 3.5 & 1.9
\end{tabular}

\footnotetext{
${ }^{6}$ A useful indicator for measuring the progress of the HIV infection relates to the level of depletion of CD4 cells. These white blood cells are an essential part of the human immune system and can be infected and destroyed by the HIV virus. One mission of the World Health Organization (WHO) is to issue guidelines defining a CD4 count threshold below which ART is recommended. The new 2013 guidelines recommend that drugs be initiated as soon as a patient's CD4 count falls below 500 cells $/ \mathrm{mm}^{3}$. Previously, the $2010 \mathrm{WHO}$ recommendation was to offer treatment at 350 CD4 cells $/ \mathrm{mm}^{3}$, and the 2006 guidelines set the threshold at 200 cells $/ \mathrm{mm}^{3}$.
} 
Source: SPECTRUM (Futures Institute, 2014)

\section{Table 2 - CD4 count and median life expectancy}

Unit costs of treatment are assumed to be constant over time and are based on Schwartländer et al. (2011). Transition from 1st line to 2nd line ART was modelled assuming that $2.64 \%$ of people on treatment switch to 2nd line therapy every year (Renaud-Théry et al., 2011). We assume no investment in prevention (prevention is introduced in the next section). Justifications for assumptions and detailed methodology used for producing estimates are explained in Appendix $1^{7}$

Table 1 shows that, country-by-country, the financial liability resulting from the moral duty to rescue is analogous to, and sometimes commensurate with, the liability of sovereign debt. For comparison, the first three columns report the prevalence of HIV, the gross domestic product (GDP) per capita and the external debt as a percentage of the GNI of each country. ${ }^{8}$

In column (4) we report the estimated cost in 2015 as a percentage of GDP. For example, in Malawi, the annual cost of ART provision in 2015 is estimated at around 3.3 per cent of GDP. These figures show that the cost of the duty to rescue is large relative to the GDP of the countries concerned.

As noted, accepting a duty to rescue for the current generation of PLHIV implies accepting a longrun flow of liabilities whose net present value can be compared to a debt. Column (5) presents the discounted present value of the cost of treatment to people currently HIV positive as a proportion of country's GDP. ${ }^{9}$ These estimates do not include the cost of future infections. They are therefore the minimum of future liabilities, in which the continuation of treatment for existing recipients is the only future liability recognised. Even with this restriction, it is apparent that for some countries the duty to rescue would constitute a very significant addition to their sovereign liabilities.

Column (5) considers only those currently HIV positive. As shown in column (6), the financial liability generated by the moral duty to rescue is substantially greater once future infections are

\footnotetext{
7 The limitations of these estimates should be emphasized. The burden created by the moral duty to rescue depends on parameters such as the future cost of ART, adherence rates, incidence and prevalence, testing rates, resistance to treatment, and the availability of a cure or a vaccine. Estimates of these parameters are currently unreliable but should gradually become better known.

${ }^{8}$ GDP data comes from IMF projections. External debt data is based on World Bank indicators.

9 The timeframe assumed is 2015 to 2050 . In order to take into account those costs likely to occur after 2050, we do a terminal value calculation (see Appendix 1 for details). The discount rate used for weighting the cost of future liabilities was set at 7 per cent: approximately the marginal return on public investment in Africa (UNCTAD, 2013). This is below the $10+$ per cent rate of return on public investment in LICs measured by Canning and Bennathan (2000). Our choice is justified in the theoretical model of section 3. By aggregating future liabilities discounted at this rate, we obtain the total amount that should be invested now to pay the future liabilities. Using such a high discount rate is conventional in policy-making (Gollier, 2011).
} 
taken into account. On average, the cost of future infection represents $38 \%$ of the total financial liability generated by the moral duty to rescue. For Malawi and Lesotho, the total liability resulting from current and future infection represents more than 40 per cent of their GDP.

An implication is that the duty to rescue generates a new quasi-debt obligation that, for an unchanged rate of infection, would accumulate over the course of a few decades to become macrosignificant. As with any such accumulation of quasi-debt, the issue of sustainability arises. Is there an ethically acceptable alternative to taking on this rising debt? Given the direct link between reducing the rate of infection and reducing the build-up of debt, the management of prevention is thus conceptually analogous to debt relief. We therefore turn from the estimation of the liability generated by the duty to rescue, to the optimal management of prevention.

\section{Rescue and Prevention}

Policy discussion of AIDS has been bedevilled by tension as to whether money should be devoted to treatment or prevention (e.g. Piot et al., 2002; Canning, 2006). This has reflected the tension between Utilitarian values, which favour prevention because it has the potential to save more people (albeit unidentified) in the future, and Prioritarian values, which privilege treatment of the most needy. We show that far from these two choices being in tension, one implication of the moral duty to rescue is an optimal allocation between prevention and treatment.

We start from the assumption advanced in Section 2 that there exists a moral duty to rescue a large majority of those who are HIV positive. Since this duty to rescue incurs an obligation, those who bear it have a rational incentive to minimize the burden. Interventions that prevent a person becoming HIV positive are worth paying as long as their cost is less than the cost of the obligation. Since the implications of this proposition are the main focus of the paper, we set it out:

Proposition 1: Money should be devoted to prevention at least up to the point at which the marginal dollar spent on prevention reduces the cost of the moral duty to rescue, as measured by the discounted cost of treatment, by one dollar.

In practice, the distinction between treatment and prevention is sometimes blurred because ART achieves both. Treatment as prevention (TasP) consists in initiating antiretroviral treatment earlier than what would be recommended on the basis of the medical needs of the patient, in order to protect partners from potential transmission. Antiretroviral drugs can also be provided to uninfected individuals as a pre-exposure prophylaxis (PreEP) to reduce HIV acquisition. Further, they can be provided to pregnant and breastfeeding women, preventing mother to child transmission (PMTCT). Finally, as a post exposure prophylaxis (PEP) shortly after an exposure to HIV they reduce the chances of infection. The preventative effect of ART implies that the provision of antiretroviral drugs does not have to be limited to those who have a claim on the moral duty to rescue. In particular, targeting PrEP and PTMCT towards individuals most likely to become infected and targeting TasP and PEP to those most likely to further transmit HIV may reduce future treatment liabilities so substantially that it fully justifies its cost. In line with our 
analysis, the provision of TasP, PrEP, PTMCT and PEP should be extended up to the point at which the marginal dollar spent on these prevention strategies reduces the cost of the moral duty to rescue by one dollar. In what follows, TasP, PrEP, PTMCT and PEP are categorized as prevention, as their provision is justified as an investment, but not directly as a moral duty. The preventative effect of antiretroviral drugs also justifies treatment to individuals who may be judged responsible for their infection and thereby to have nullified the duty to rescue. Treatment of sex workers can be especially effective in reducing future liabilities.

To investigate the interdependences between treatment and prevention and demonstrate proposition 1, we use a simple two-period model. We consider a single country characterized by an HIV epidemic in the form of a two-period susceptible-infected model, or SI model. At time 0, a share $S_{0}$ of the population is uninfected (or susceptible), and a share $I_{0}$ is HIV infected. The population at time 0 is normalized to 1 such that $I_{0}=1-S_{0}$. HIV is a deadly disease and people at an advanced stage of infection are at risk of dying. Among those who are HIV positive, a share $a_{0}$ is asymptomatic and do not need treatment to survive till period 1 . The remainder, with share $\left(1-a_{0}\right)$, needs ART to remain alive in period 1 . The government determines the proportion $t_{0}$ of people in need who receive ART in period 0 . According to the moral duty to rescue, $t_{0}$ should be equal to 1 .

From period 0 to period 1, new infections occur. Incidence $N_{0}$ between the two periods depends first on the coverage of ART and second on the level of prevention in period $0, p_{0}$. Without ART, the transmission rate of PLHIV is $b^{h}$. For people on ART, the transmission rate of HIV is denoted $b^{l}$. Because ART reduces the transmission rate of HIV (Cohen et al. 2011), we assume $b^{h}>b^{l}$. In our SI model, new infections are therefore equal to:

$N_{0}=\left(1-p_{0}\right)\left[b^{l}\left(1-a_{0}\right) t_{0} I_{0}+b^{h}\left(a_{0} I_{0}+\left(1-a_{0}\right)\left(1-t_{0}\right) I_{0}\right)\right] S_{0}$.

The first term in square brackets captures the infectivity of individuals on ART (low transmission rate $b^{l}$ ) The second term in square brackets represents the infectivity of asymptomatic individuals and individuals needing ART but not receiving it (high transmission rate $b^{h}$ ). A share $d$ of individuals needing treatment dies if they do not get ART.

In period 1, the number of uninfected individuals is $S_{1}=S_{0}-N_{0}$. The number of infected individuals is given by $I_{1}=I_{0}+N_{0}-I_{0}\left(1-a_{0}\right)\left(1-t_{0}\right) d$. The number of people needing treatment in period 1 is equal to the number of people who needed treatment in period 0 and who survived, plus a proportion $\left(1-a_{1}\right)$ of people who are infected in period 1 and who did not need ART in period 0 .

The complementarity between prevention and treatment can be illustrated within this framework. Let us assume that the government recognizes the moral duty to rescue and therefore imposes full 
coverage of ART, that is, $t_{0}=t_{1}=1$. If the unit cost of ART is equal to $\pi^{t},{ }^{10}$ the total cost of the moral duty to rescue will be equal to $\left(1-a_{0}\right) I_{0} \pi^{t}$ in period 0 and $\left[\left(1-a_{0}\right) I_{0}+\right.$ $\left.\left(1-a_{1}\right)\left(a_{0} I_{0}+N_{0}\right)\right] \pi^{t}$ in period 1 . As incidence $N_{0}$ is a decreasing function of prevention, $p_{0}$, prevention can be used to diminish the total cost of the moral duty to rescue. Only the cost of future infection is affected by prevention. It is therefore helpful to conceptualize the total cost of the rule of rescue as having a fixed part, which depends on past infections, and a variable part which arises in the future and which can be optimized thanks to prevention. As shown in Table 1, this latter part represents 22-53 per cent of the total cost induced by the moral duty to rescue for the eight countries considered.

In order to optimize prevention, its cost has to be characterized. It is constituted of two elements. First, the implementation of prevention programmes has a direct cost. Because prevention methods vary in cost-effectiveness and the costs of reaching different populations varies, the cost of prevention is expected to be an increasing and convex function $c\left(p_{0}\right)$ of prevention.

Second, money invested in prevention has an opportunity cost. If the government is not budget constrained in period 0 , the opportunity cost of investing in prevention is determined by the marginal rate of return on alternative investments. If, however, the government has to borrow to finance prevention efforts in period 0 , it faces the cost of debt servicing in period 1 . We assume that the marginal interest rate on investment is equal to the cost of borrowing and denote this rate $r$.

In order to optimize prevention, the government has to minimize the following objective function:

$$
\min _{p_{0}}\left[\left(1-a_{0}\right) I_{0}+\left(1-a_{1}\right)\left(a_{0} I_{0}+N_{0}\right)\right] \pi^{t}+(1+r) c\left(p_{0}\right)
$$

where $N_{0}$ is given by equation (1). The associated first-order condition can be expressed as follows:

$\frac{\left(1-a_{1}\right)\left[a_{0}\left(b^{h}-b^{l}\right)+b^{l}\right] I_{0}\left(1-I_{0}\right) \pi^{t}}{(1+r)}=c\left(p_{0}\right)^{\prime}$

The left-hand side of this equation represents the marginal discounted cost of ART treatment. The right-hand side is the marginal cost of prevention. The two sides of this equation and its solution are represented in figure 1.

\footnotetext{
${ }^{10}$ As for estimates in section 3, the marginal cost of ART is assumed to be constant. Indeed, the literature is unclear how the extension of ART coverage might affect its marginal cost, reducing it through economies of scale and scope (e.g. Siapka et al. 2014) or increasing it due to difficulties in reaching some individuals (e.g. Meyer-Rath and Over, 2012).
} 


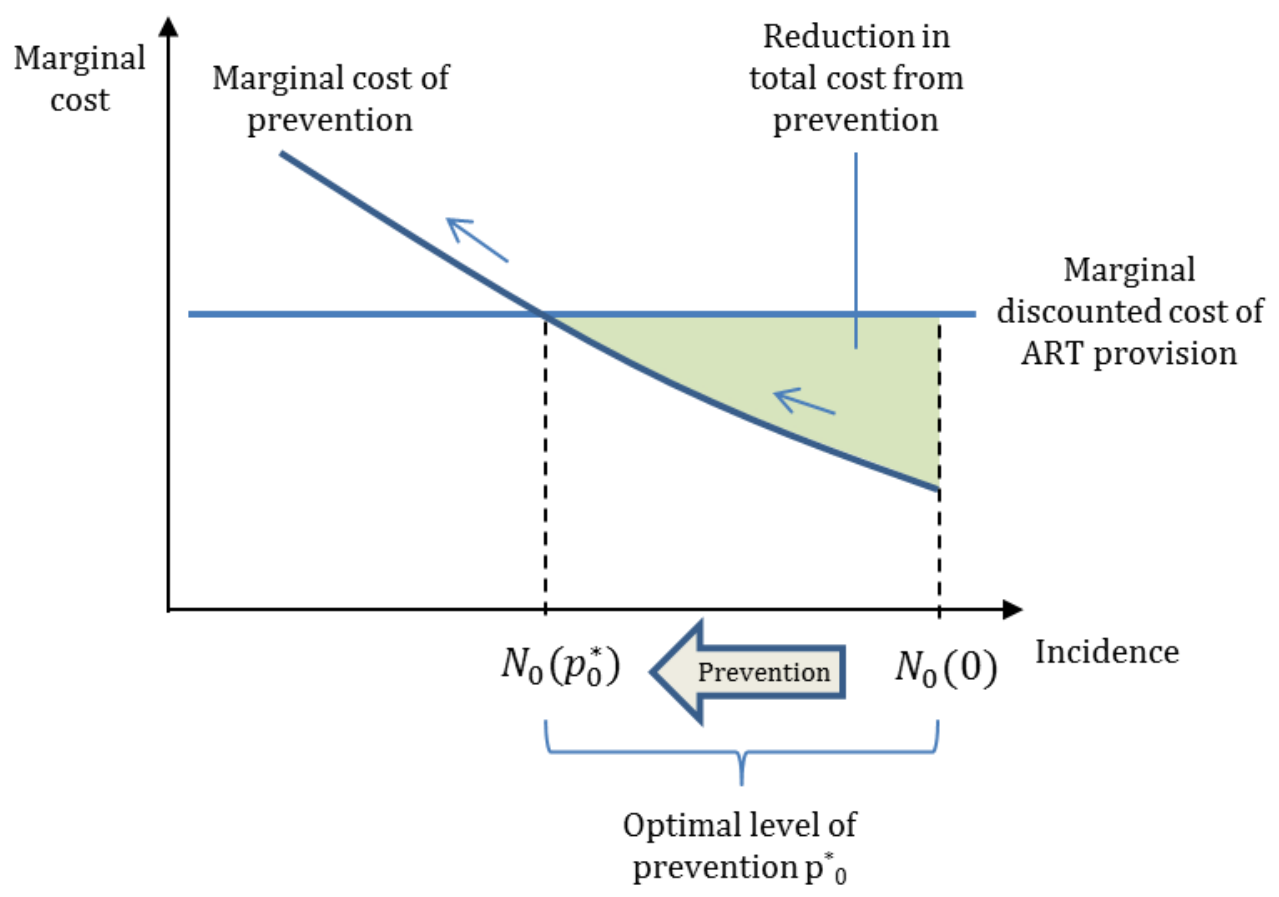

Figure 1: Optimizing prevention to reduce the financial burden created by the moral duty to rescue.

Formally, solving the first-order condition gives the optimal level of prevention:

$p_{0}^{*}=c^{\prime-1}\left(\frac{\left(1-a_{1}\right)\left[a_{0} b^{h}+\left(1-a_{0}\right) b^{l}\right] I_{0}\left(1-I_{0}\right) \pi^{t}}{(1+r)}\right)$

Five corollaries can be derived from the comparative statics of $p_{0}^{*}$.

Corollary $1 \frac{\delta p_{0}^{*}}{\delta c^{\prime}}<0, \frac{\delta p_{0}^{*}}{\delta \pi^{t}}>0$ : The optimal level of prevention is decreasing in its marginal cost and is increasing in the cost of treatment. The higher the cost of prevention, the lower the attractiveness of investment in prevention. The higher the future cost the moral duty to rescue, the higher the incentive to invest in prevention.

Corollary $2 \frac{\delta p_{0}^{*}}{\delta r}<0$ : Prevention is decreasing in the discount rate/marginal interest rate. If the marginal interest rate is high, the opportunity cost of prevention is high, and the optimal prevention level will be correspondingly lower.

Corollary $3 \frac{\delta p_{0}^{*}}{\delta b^{l}}>0, \frac{\delta p_{0}^{*}}{\delta b^{h}}>0$ : The optimal level of prevention is increasing in the transmission rate of HIV, both with and without ART. Investing in prevention is more important if infectivity of HIV is high. 
Corollary $4 \frac{\delta p_{0}^{*}}{\delta a_{0}}>0$ : The optimal prevention level is decreasing in the proportion of PLHIV who need treatment in period 0. If HIV is considered in a dynamical framework, the proportion of PLHIV needing treatment in period 0 is expected to be low, either in the early stage of the increase in ART coverage, or if the CD4 count threshold determining who has access to free ART is low. In this case, many PLHIV initially have too high a CD4 count to be eligible for ART. As their infectivity is expected to be high without ART, high investment in prevention will be needed. Conversely, if the proportion of PLHIV needing treatment in period 0 is high, the average infectivity of PLHIV will be low and investment in prevention should be lower.

Corollary $5 \frac{\delta p_{0}^{*}}{\delta a_{1}}<0$ : Prevention is increasing in the proportion of people newly infected who need ART. If PLHIV need ART early on, the cost the moral rule of rescue will be increased, thereby increasing the attractiveness of prevention. This will be the case if the CD4 count threshold that determines eligibility for ART is set high.

Taken together, Corollaries 4 and 5 imply that the relationship between optimal prevention and the CD4 count threshold determining eligibility is ambiguous and so can only be determined empirically.

Given the reduced transmission rate of HIV while on ART, (Cohen et al. 2011), the increase in the coverage of ART implied by acceptance of the moral duty to rescue is likely to put the trajectory of the HIV disease on a decreasing trend. Within our theoretical framework, accepting the moral duty to rescue is equivalent to imposing $t_{0}=t_{1}=1$. This has two opposite effects on the number of PLHIV. Mortality from HIV is lowered, thereby increasing the number of PLHIV. However, the reduced infectivity of PLHIV who are on ART is expected to reduce incidence and hence reduce the number of PLHIV. As shown with simulations in section 6, this latter effect is expected to be more important than the former in the long run, especially if prevention is introduced as determined in equation (4).

As explained in section 2, the moral duty to rescue is an undemanding moral framework, and so is likely to be widely accepted by OECD populations. In contrast, the moral framework of Universalist Utilitarianism, often used in health economics, is radically more demanding and so a democratically empowered electorate is unlikely to accept the myriad of redistributive actions that would follow from it. Hence, actions warranted according to the moral duty to rescue framework set a lower bound for guiding the response against HIV. The warranted actions which we have derived also constitute a lower bound because the moral duty to rescue framework does not consider the adverse effects on those kept alive by treatment. HIV has a wider impact than on the immune system, affecting mental health, and potentially inducing stigma and fear. Further, the side-effects of treatment worsen with age. HIV is now a long-term chronic disease for many patients so that the HIV-patient population is ageing. Older patients are increasingly suffering from age-related non-communicable diseases associated with HIV-infection and treatment (Smit et al. 2015). The additional costs of these sides-effects and co-morbidities are not incorporated in the 
estimates used in this paper because they may not meet the criteria that trigger the moral duty to rescue. Nevertheless, these further potential costs underline the significance of HIV-infection as a costly life-long condition. Governments wanting to be more generous than the moral duty to rescue framework could take these adverse consequences into account. According to Corollary 1, this would increase the optimal investment in prevention. Our estimates thereby provide a lower bound for the liabilities that governments will face in terms of prevention and treatment.

In this section, we showed that, analogous to any other inter-temporal optimization problem, investment in prevention should be increased up to the point at which its marginal cost equals the marginal reduction in the discounted total liability created by the moral duty to rescue. In the next section, we extend this model to a two-country framework to discuss how investment in prevention should be apportioned between high prevalence countries and the international community.

\section{Global Solidarity: Apportioning the Moral Duty to Rescue and Expenditure on HIV Prevention}

Funding for HIV/AIDS from both domestic and international sources has grown rapidly over the past decade. By 2012 an estimated \$18.9bn was spent on HIV programs in low- and middle-income countries. This was almost equally split between domestic and international sources, with the former accounting for 53 per cent. ${ }^{11}$ However, this global picture masks considerable variation between countries, depending on the size of their economy and the burden of HIV. A study by the Results for Development Institute for PEPFAR reports that for nine high-prevalence African LMICs and LICs, if domestic resources rose at the rate of expected economic growth during 201216, dependence on external resources would vary within the range 84-99 per cent, (R4D, 2013). External funding increases with HIV prevalence and decrease with GNI per capita (Sterck, 2017), implying that dependence on external sources of finance will remain a feature of HIV/AIDS financing for many poorer high prevalence countries for a very considerable time.

We therefore investigate how obligations might be shared between the citizens of high-prevalence poor countries and those of richer countries. This section relies on the assumption that the affected country is too poor to bear the liability created by the moral duty to rescue in its entirety. In this case, the international community accepts (part of) the moral duty to rescue, and we assume that this commitment is credible. ${ }^{12}$

\footnotetext{
11 The range of estimates is $\$ 16.6-21.2 \mathrm{bn}$.

12 If this key assumption is not verified, the HIV positive population of the poor and high prevalence country does not get access to free ART because its government does not have the means to fulfill the moral duty to rescue, and because the international community denies its moral obligation.
} 
One important principle should guide the apportionment of treatment of future infections relative to prevention as between donors and the affected countries such as to keep incentives aligned with the optimization of section 3 and avoid underfinancing of prevention.

Proposition 2: to avoid moral hazard, the donor must apply a broadly similar distribution of burden-sharing to treatment of future infection and prevention.

If the international community accepts to finance a share $\sigma$ of the liability created by the treatment of future infection, it should also support at least a share $\sigma$ of prevention efforts. Only this strategy for dividing responsibility can avoid moral hazard. If, for example, donors entirely funded the treatment of future infections while African governments were to fund prevention, there would be too little incentive for the latter to invest in prevention.

The model can be used to demonstrate the moral hazard problem. Let us assume that the sharing rule is such that the donor country pays a share $\sigma^{t 1}$ of the cost of ART in period 1 . In this case, the minimization programme that the recipient country uses to determine its optimal level of prevention will be affected. Because the cost of ART is shared in period 1, the first term in equation (2) is multiplied by $\left(1-\sigma^{t 1}\right)$ :

$\min _{p_{0}}\left(1-\sigma^{t 1}\right)\left[\left(1-a_{0}\right) I_{0}+\left(1-a_{1}\right)\left(a_{0} I_{0}+N_{0}\right)\right] \pi^{t}+\left(1+r^{R}\right) c\left(p_{0}\right)$

The resulting optimal prevention level is reduced compared to the benchmark model:

$$
p_{0}=c^{\prime-1}\left(\frac{\left(1-\sigma^{t 1}\right)\left(1-a_{1}\right)\left[a_{0} b^{h}+\left(1-a_{0}\right) b^{l}\right] I_{0}\left(1-I_{0}\right) \pi^{t}}{\left(1+r^{R}\right)}\right)<p_{0}^{*}
$$

One way to solve this moral hazard problem is for the donor also to pay a share $\sigma^{p}$ of the prevention efforts in period 0 . In this case, the second term in equation (5) is also multiplied by $\left(1-\sigma^{p}\right)$. With this adjustment, the optimal level of prevention is given by:

$p_{0}=c^{\prime-1}\left(\frac{\left(1-\sigma^{t 1}\right)\left(1-a_{1}\right)\left[a_{0} b^{h}+\left(1-a_{0}\right) b^{l}\right] I_{0}\left(1-I_{0}\right) \pi^{t}}{\left(1-\sigma^{p}\right)\left(1+r^{R}\right)}\right)$

If $\sigma^{t 1}=\sigma^{p}$, prevention efforts will be equal to $p_{0}^{*}$, which proves proposition 3 .

In practice, this simple rule may be slightly affected by the fact that discount rates are different in donors and recipient countries. Because their discount rate is lower, the incentive for donors to invest in prevention is higher (Corollary 2 above). The donor country would therefore wish to increase its contribution to prevention beyond its share of future treatment. However, in reaction, the recipient country would reduce its own contribution to prevention. Despite this, if the donor has to pay a large share of the cost of future infections, the benefit to the donor of the net increase in prevention may exceed the cost induced by the recipient's underinvestment in prevention. In this case, the donor country may rationally invest more in prevention than its share of treatment. 
We illustrate how this mechanism would work within our two-period model. If the donor country changes its contribution $\sigma^{p}$ to prevention efforts, the reaction of the recipient country is given by equation (7). Given this reaction function, it is optimal for the donor to minimize the net present value of its contribution, taking its own discount rate into account.

$\min _{\sigma^{p}} \sigma^{t}\left[\left(1-a_{0}\right) I_{0}+\left(1-a_{1}\right)\left(a_{0} I_{0}+N_{0}\right)\right] \pi^{t}+\left(1+r^{D}\right) \sigma^{p} c\left(p_{0}\right)$

In order to obtain a closed form solution to this minimization programme, we need to specify the cost function, $c\left(p_{0}\right)$. Let us assume that it is a quadratic function of investment in prevention: $c\left(p_{0}\right)=\pi^{p} p_{0}{ }^{2}$. With this assumption, we obtain that the optimal investment in prevention for the donor country is given by:

$\sigma^{p^{*}}=\frac{2\left(1+r^{R}\right) \sigma^{t}-\left(1+r^{D}\right)\left(1-\sigma^{t}\right)}{2\left(1+r^{R}\right) \sigma^{t}+\left(1+r^{D}\right)\left(1-\sigma^{t}\right)}$

We have that $\sigma^{p^{*}}>\sigma^{t}$ if:

$\sigma^{t}>\frac{1+r^{R}}{\left(1+r^{R}\right)+\left(r^{R}-r^{D}\right)}$

If the marginal interest rate in donor country is 3 per cent and the marginal interest rate in recipient country is 7 per cent, the right-hand side of this inequality is equal to 93 per cent. In words, this tells us that if in period 1 the donor country has to pay at least 93 per cent of the cost of the moral duty to rescue, it is then optimal for it to invest more than its fair share $\sigma^{t}$ in prevention. Indeed, because the donor has a lower discount rate, it values prevention more than the recipient. However, if the donor increases its contribution $\sigma^{p}$ to prevention, it will be rational for the recipient to reduce its own investment in prevention. Nevertheless, when inequality (10) is satisfied, the former effect is stronger than the latter and it is optimal for the donor country to overinvest in prevention.

\section{Simulations for Malawi}

In section 3, we showed that prevention can be understood as an investment in the reduction of future liabilities brought about by the moral duty to rescue. In Proposition 1, we derived an optimal decision rule which states that prevention should be increased up to the point at which the marginal dollar spent in prevention equals the marginal cost of the duty to rescue. In practice, the cost of the duty to rescue is determined by the annual cost of ART cumulated over time and discounted over the expected duration of treatment. Matching this cost to the marginal benefits of prevention is likely to be empirically complex. For each possible intervention that prevents HIV infection, a schedule of the marginal efficacy of expenditure must be estimated. Such analysis must be contextspecific as there is no global, or even African, marginal cost of treatment, or marginal efficacy of prevention (Anderson et al. 2014). As several prevention interventions with reinforcing benefits exist in each context, an optimal mix of interventions need to be considered when selecting prevention interventions. This analysis also needs to go beyond the health sector as narrowly 
conceived, as many effective prevention strategies are multi-sectorial in nature (Remme et al., 2014). To our knowledge, there is as yet no epidemiological model sufficiently sophisticated for such an optimization.

While it is beyond the scope of the present analysis to build such a model, we illustrate what its potential might be by focusing on two prevention strategies, treatment-as-prevention and circumcision. We focus on Malawi because it exemplifies the situation facing low-income countries with high HIV prevalence and use SPECTRUM to illustrate how these prevention strategies could be used to minimize the cost of the duty to rescue.

A brief disclaimer is necessary. The data requirement to undertake this simulation exercise is massive. For example, data on the cost of circumcision and treatment is needed for all coverage rates and over time. Such data are not currently available, implying that simulations rely on hypotheses on the shape of these costs. Given these uncertainties, we therefore put the emphasis on the mechanisms underlying our results rather than on the exact numbers derived from our simulation exercise.

International finance for HIV in Malawi has been focused overwhelmingly on delivering ART. Given this, as awareness of prevention has increased, institutionally the easiest way of increasing international expenditure on prevention has been to raise the CD4 count at which treatment is provided. This indeed has a preventative effect (Cohen, 2011). As explained in section 2, our paper assumes that the moral duty to rescue kicks in once the CD4 count falls below the $350 \mathrm{cells} / \mathrm{mm}^{3}$ threshold. Hence, our paper implicitly interprets any increase in the CD4 count threshold above 350 cells $/ \mathrm{mm}^{3}$ as being a prevention strategy. The issue then becomes whether such a prevention strategy sufficiently reduces future infections that it reduces the overall burden of the duty of rescue. In investigating this issue, as previously we used SPECTRUM, estimating the total cost of ART provision for different CD4 count thresholds. As shown in Figure 3, we find that ART as prevention is not sufficiently effective to reduce the quasi-liability generated by the moral duty to rescue. In this it contrasts with most existing studies on the cost-effectiveness of earlier eligibility for ART which usually conclude that treatment-as-prevention is a very cost-effective prevention strategy (Eaton et al., 2014; Walensky et al, 2013). While our analysis is meant to be illustrative rather than definitive, it is worth noting why our results are so different. The criterion in these other studies is cost-'effectiveness'. For example, Walensky et al. (2013) and Eaton et al. (2014) classified early ART as cost-effective if its incremental cost per DALY averted or per life-year saved was less than three times annual per capita GDP. In comparison, the moral framework introduced in this paper requires prevention to be cost-saving: the net present value of investments in prevention should be lower that the net present value of the ensuing reduction in the cost of the moral duty to rescue. In other words, the value of an infection averted is given by the cost of ART provision. Additionally, the discount rate used in the global health literature is usually lower, set at 3 per cent, implying that current investments in prevention are more valued than in our framework. However, while such a low discount rate may be a reasonable assumption for a donor, 
it clearly does not characterize the discount rate used by African governments for their own spending programs.

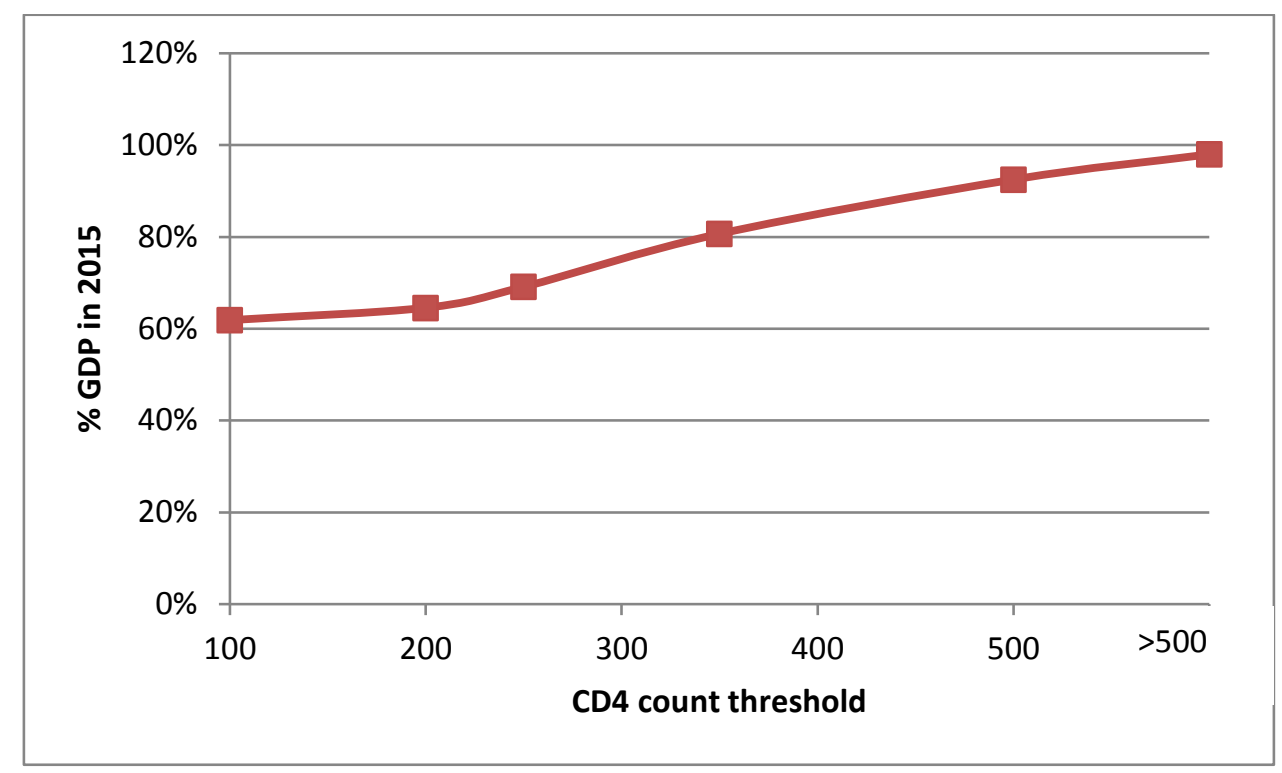

Figure 3: NPV of the cost of ART as a percentage of GDP as a function of the CD4 count threshold for Malawi

Circumcision has been shown to reduce by 60 per cent the risk of acquiring an HIV infection for men (Auvert et al. 2005; Bailey et al., 2007). We show that the total cost of the moral duty to rescue can be considerably reduced by investing in circumcision. To reach this conclusion, we start from the 'no prevention' scenario of section 3 and increase circumcision rates step by step in order to assess how circumcision can be used as an investment strategy to reduce future liabilities.

According to our estimates, increasing circumcision coverage is a very cost effective prevention strategy for Malawi (Table 3). This strategy would require making a considerable initial investment to achieve a quantum increase in the coverage of circumcision. This initial investment is worth doing because the reduced incidence and prevalence that it generates would significantly diminish the subsequent yearly cost of the duty to rescue. An investment of \$267 million in 2015 to increase circumcision coverage would reduce the net present value of the cost of ART provision by $\$ 734$ million. The net pay-off of this investment would be worth $\$ 468$ million; the total liability brought about by the duty to rescue - i.e. the net present value of ART and circumcision costs would be reduced from $\$ 4.02 \mathrm{bn}$ to $\$ 3.55 \mathrm{bn}$. This apparent underfunding of prevention by means of circumcision, juxtaposed against over-funding of prevention by means of a high CD4 count, may reflect institutional biases generated by the partition between donor and government financing of health policies. 


\begin{tabular}{c|cc|} 
& \multicolumn{2}{|c|}{$\begin{array}{c}\text { Total cost (ART + } \\
\text { circumcision) } \\
\text { 350 CD4/mm3 }\end{array}$} \\
$\begin{array}{c}\text { Circumcision } \\
\text { coverage }\end{array}$ & $\begin{array}{c}\text { In million } \\
\text { USD }\end{array}$ & \% GDP 2015 \\
\hline Baseline (22\%) & 4,019 & 80.7 \\
$30 \%$ & 3,966 & 79.6 \\
$40 \%$ & 3,900 & 78.3 \\
$50 \%$ & 3,836 & 77.0 \\
$60 \%$ & 3,774 & 75.7 \\
$70 \%$ & 3,714 & 74.5 \\
$80 \%$ & 3,657 & 73.4 \\
$90 \%$ & 3,603 & 72.3 \\
$100 \%$ & 3,552 & 71.3 \\
\hline Source: authors' calculations & & \\
\hline
\end{tabular}

Table 3 - Estimates of the total cost of treatment and prevention for different circumcision coverage

The gain from circumcision varies according different parameters. Illustrating Corollary 1 derived from the theoretical model in section 4, Figures 4 (a) and (b) show that the benefit from investing in circumcision is increasing in the cost of ART and decreasing in the cost of circumcision. Similarly, Figures 4 (c) shows that the benefit from investing in circumcision is decreasing in the discount rate (marginal interest rate), as derived in Corollary 2. The latter indeed represents the opportunity cost of investments in prevention.

From Figure 4 (d), we also conclude that the return to investment in circumcision in Malawi is an inverted U-shaped function of the CD4 count threshold defining the moral duty to rescue. As explained in section 4, two opposite effects are at play. On the one hand, a high CD4 count threshold reduces the average infectivity of PLHIV, thereby reducing the need for prevention (Corollary 4). On the other hand, a high CD4 count threshold increases the expected cost of people not yet on treatment, thereby increasing the value of prevention (Corollary 5). In the case of circumcision in Malawi, the first mechanism seems to be stronger when the CD4 count threshold is high, and the second mechanism is stronger when the CD4 count threshold is low.

While our results show that prevention can be used to minimize the liability induced by the duty of rescue, they also show that the amount that will have to be paid remains very high. One reason for this is that a large part of the cost of the duty to rescue - 64\% in the case of Malawi - comes from people who are already infected. Evidently, prevention can have no effect on the cost of treating those already infected. 


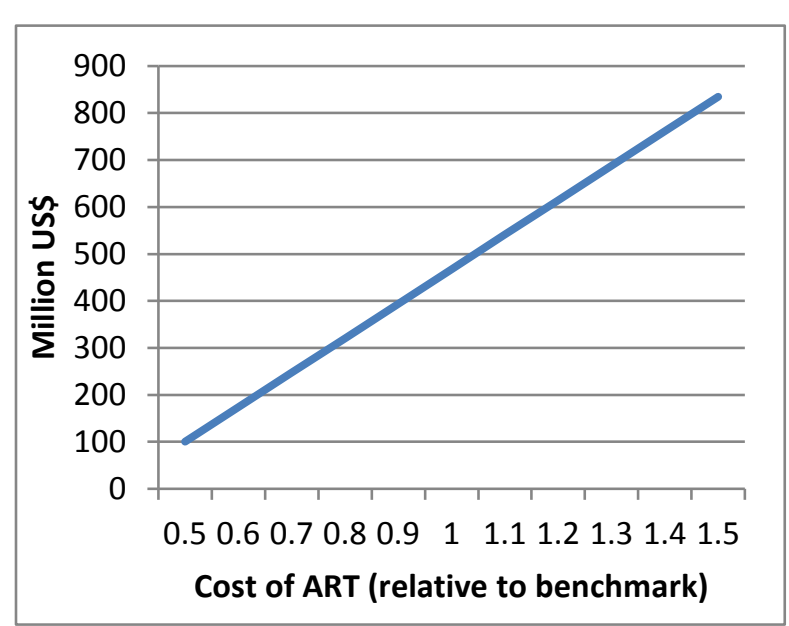

(a) As a function of the cost of ART

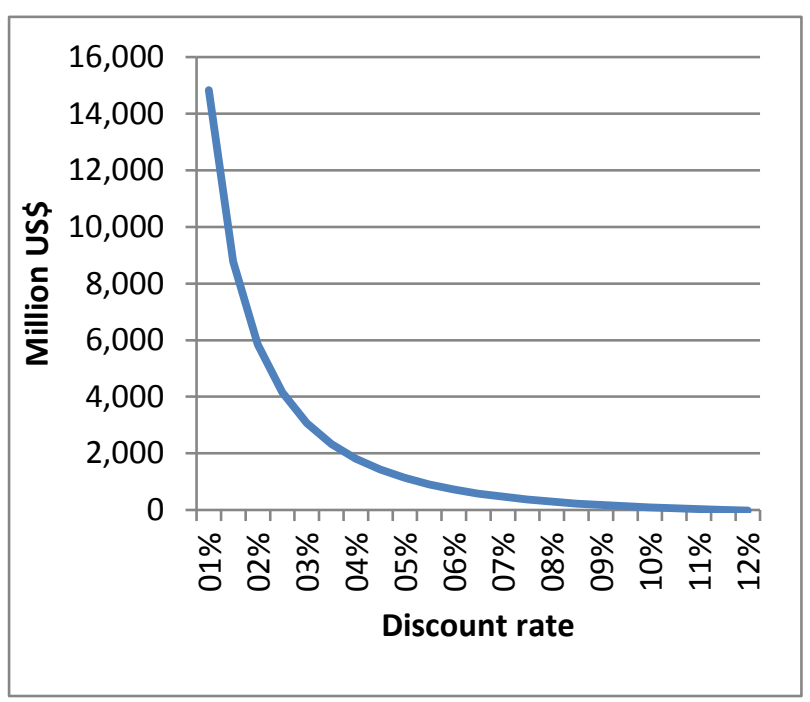

(c) As a function of the discount/marginal interest rate threshold

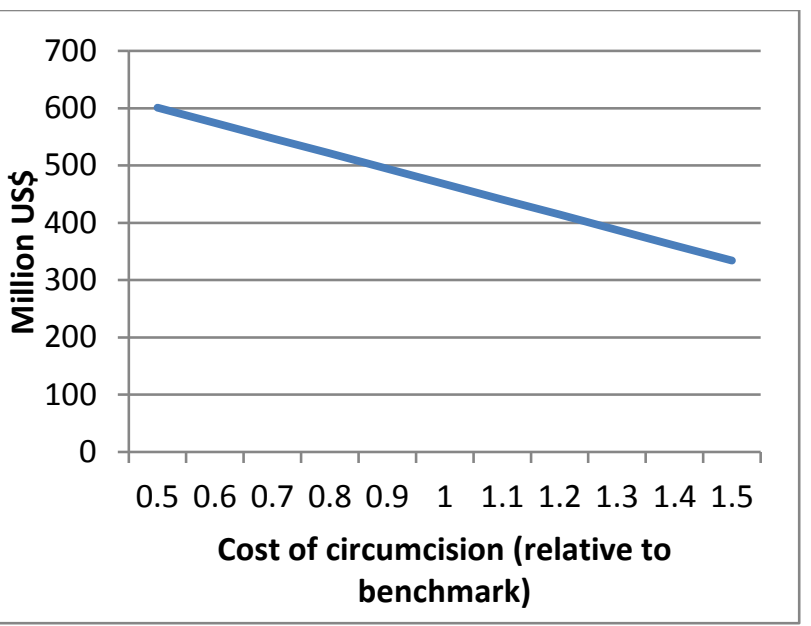

(b) as a function of the cost of circumcision

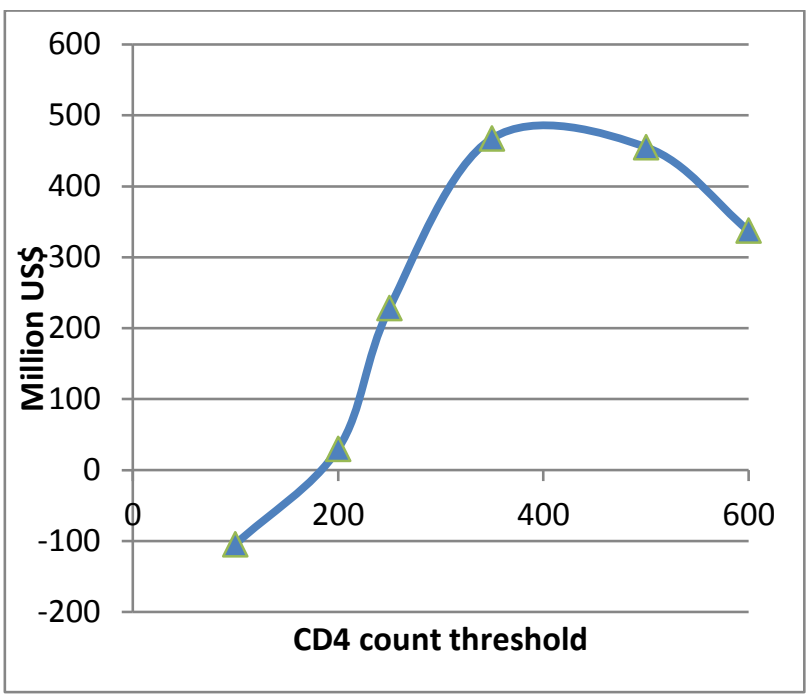

(d) as a function of the CD4 count

Figure 4: reduction in the total cost of the moral duty of rescue from circumcision - 350 cells $/ \mathrm{mm}^{3}$ threshold.

\section{Conclusion}

In this paper we have explored the implications of a moral duty of rescue for the treatment and prevention of HIV. In democracies, public policy can be expected to reflect prevailing norms. In contrast to Utilitarianism, a moral duty to rescue is, we suggest, very widely recognized in most societies. Hence, its implications can have real purchase on public policy. Further, the distinctive features of HIV make the moral duty to rescue particularly pertinent: the decision whether or not to provide ART is tantamount to deciding whether a clearly specified group of identifiable people should live or die. It should therefore be possible to get broad ethical consensus on the need to 
keep HIV+ people alive by means of treatment, even if there is no such consensus on less sharply defined possible policies. In effect, recognition of the duty to rescue people who are HIV+ is moral minimalism, and as such is highly convenient for policy making in a democracy. The policies that follow from it are not dependent upon the imposition of a moral standard that is not widely shared.

While ethically minimalist, the duty to rescue has powerful and non-obvious implications. The first is that because ART treatment is an irreversible commitment which must continue for many years, almost all the costs of the decision lie in the future and so it incurs a liability analogous to a debt. We show that for some African countries this quasi-debt is very substantial, and indeed may make them debt-distressed.

The key step in the paper has been to show that because the moral duty to rescue generates a substantial quasi-debt, it also generates the criterion by which to determine the minimum efficient level of expenditure on prevention. Prevention policies should be pursued at least up to the point at which expenditure on them reduces the debt burden sufficiently to minimize the overall cost of accepting the duty to rescue.

Importantly, we show that whatever division of the total financial burden between the governments of poor countries and the international community is determined, a broadly similar distribution of burden-sharing should apply to the treatment of future infections and prevention. Any other assignment of the financial costs of prevention will generate moral hazard and so potentially give rise to inefficient resource allocation.

\section{Acknowledgements}

This work was supported by the Rush Foundation. This paper was written as part of RethinkHIV. We specifically thank Rifat Atun, Angela Chang, Markus Haacker, Tim Hallett, Judith Kabajulizi, David Miller, Mthuli Ncube, Osondu Ogbuoji, Michelle Remme, Sachin Silva, Mariana Siapka, Mikaela Smit, Anna Vassall, Charlotte Watts and Alan Whiteside for useful comments and discussions.

\section{References}

Atun, R., Chang, A. Y., Ogbuoji, O., Silva, S., Resch, S., Hontelez, J., and Bärnighausen, T. (2016). Long- term financing needs for HIV control in sub- Saharan Africa in 2015-2050: A modelling study. BMJ Open, 6. e009656.

Anderson, S.-J., Cherutich, P., Kilonzo, N., Cremin, I., Fecht, D., Kimanga, D., ... Hallett, T. B. (2014). Maximising the effect of combination HIV prevention through prioritisation of the people and places in greatest need: a modelling study. The Lancet, 384, 249-256

Auvert, B., Taljaard, D., Lagarde, E., Sobngwi-Tambekou, J., Sitta, R., and Puren, A. (2005). Randomized, controlled intervention trial of male circumcision for reduction of HIV infection risk: the ANRS 1265 Trial. PLoS medicine, 2, e298. 
Bailey, R. C., Moses, S., Parker, C. B., Agot, K., Maclean, I., Krieger, J. N., ... and Ndinya-Achola, J. O. (2007). Male circumcision for HIV prevention in young men in Kisumu, Kenya: a randomised controlled trial. The Lancet, 369, 643-656.

Burke, M., Gong, E., and Jones, K. (2014). Income shocks and HIV in Africa. The Economic Journal. 125, 1157-1189.

Canning, D. (2006). The economics of HIV/AIDS in low-income countries: the case for prevention. The Journal of Economic Perspectives, 20: 121-142.

Canning, D., and Bennathan, E. (2000). The social rate of return on infrastructure investments. World Bank Policy Research Working Paper, 2390.

Cohen, M. M. S., Chen, Y. Y. Q., McCauley, M., Gamble, T., Hosseinipour, M. C., Kumarasamy, N., Fleming, T. R. (2011). Prevention of HIV-1 infection with early antiretroviral therapy. The New England Journal of Medicine, 365, 493-505.

Council on Foreign Relations (2012). Public opinion on Global Issues. CFR.org, New York.

Eaton, J. W., Menzies, N. a, Stover, J., Cambiano, V., Chindelevitch, L., Cori, A., ... Hallett, T. B. (2014). Health benefits, costs, and cost-effectiveness of earlier eligibility for adult antiretroviral therapy and expanded treatment coverage: a combined analysis of 12 mathematical models. The Lancet Global Health, 2, e23-34.

Fortson, J. G. (2011). Mortality risk and human capital investment: The Impact of HIV/AIDS in sub-Saharan Africa. The Review of Economics and Statistics, 93, 1-15.

Futures Institute (2014). Spectrum Manual. Spectrum System of Policy Models.

Futures Institute. Spectrum. http://www.futuresinstitute.org/spectrum.aspx (accessed November 2, 2014).

Galárraga, O., Wirtz, V. J., Santa-Ana-Tellez, Y., \& Korenromp, E. L. (2013). Financing HIV programming: how much should low-and middle-income countries and their donors pay. PloS one, 8, e67565.

Gollier, C. (2011). Pricing the future: The economics of discounting and sustainable development. Princeton University Press pp. 1-210.

Haacker, M. (Ed.). (2004). The macroeconomics of HIV/AIDS. International Monetary Fund.

Haacker, M. (2011). HIV/AIDS as a Fiscal Liability. In Proceedings of the German Development Economics Conference, Berlin 2011 (No. 35). Verein für Socialpolitik, Research Committee Development Economics.

Haidt, J. (2012). The righteous mind: Why good people are divided by politics and religion. New York: Pantheon.

Kalemli-Ozcan, S. (2012). AIDS, "reversal" of the demographic transition and economic development: evidence from Africa. Journal of Population Economics, 25, 871-897.

Kremer, M. (1996). Integrating Behavioral Choice into Epidemiological Models of AIDS. The Quarterly Journal of Economics, 111, 549-573. 
Lule, E., and Haacker, M. (2011). The Fiscal Dimension of HIV/AIDS in Botswana, South Africa, Swaziland, and Uganda: Experiences from Botswana, South Africa, Swaziland, and Uganda. World Bank Publications.

Mankiw, N. Gregory, and Matthew Weinzierl (2010). "The optimal taxation of height: A case study of utilitarian income redistribution." American Economic Journal: Economic Policy, 2, 155176.

Meyer-Rath, G., and Over, M. (2012). HIV treatment as prevention: modelling the cost of antiretroviral treatment—state of the art and future directions. PLoS medicine, 9, e1001247.

Munthali, C., Taegtmeyer, M., Garner, P. G., Lalloo, D. G., Squire, S. B., Corbett, E. L., ... MacPherson, P. (2014). Diagnostic accuracy of the WHO clinical staging system for defining eligibility for ART in sub-Saharan Africa: a systematic review and meta-analysis. Journal of the International AIDS Society, 17, 18932.

Oster, E. (2005). Sexually transmitted infections, sexual behavior, and the HIV/AIDS epidemic. The Quarterly Journal of Economics, 120, 467-515.

Oster, E. (2012). Routes of infection: exports and HIV incidence in Sub- Saharan Africa. Journal of the European Economic Association, 10, 1025-1058.

Over, M. (2012). Achieving an AIDS transition: Preventing infections to sustain treatment. CGD Books.

Pinker, S. (2007). The stuff of thought: Language as a window into human nature. Penguin.

Piot, P., Zewdie, D., and Türmen, T. (2002). HIV/AIDS prevention and treatment. The Lancet, 360, 86-88.

Pongou, R., and Serrano, R. (2013). Fidelity networks and long-run trends in HIV/AIDS gender gaps. The American Economic Review, 103, 298-302.

R4D (2013). Financing National AIDS Responses for Impact, Fairness, and Sustainability: A Review of 12 PEPFAR Countries in Africa, Mimeo.

Resch, S., Ryckman, T., and Hecht, R. (2015). Funding AIDS programmes in the era of shared responsibility: an analysis of domestic spending in 12 low-income and middle-income countries. The Lancet Global Health, 3, e52-e61.

Renaud-Théry, F., Avila-Figueroa, C., Stover, J., Thierry, S., Vitoria, M., Habiyambere, V., and Souteyrand, Y. (2011). Utilization patterns and projected demand of antiretroviral drugs in lowand middle-income countries. AIDS research and treatment, 1-8.

Remme, M., Vassall, A., Lutz, B., Luna, J., and Watts, C. (2014). Financing structural interventions: going beyond HIV-only value for money assessments. AIDS, 28, 425-434.

Remme, M., Siapka, M., Sterck, O., Ncube, M., Watts, C., and Vassall, A. (2016). Financing the HIV response in sub-Saharan Africa from domestic sources: moving beyond a normative approach. Social Science \& Medicine, 169, 66-76. 
Rulli, T., \& Millum, J. (2016). Rescuing the duty to rescue. Journal of Medical Ethics, 42, 260264.

Schwartländer, B., Stover, J., Hallett, T., Atun, R., Avila, C., Gouws, E., ... \& Alsallaq, R. (2011). Towards an improved investment approach for an effective response to HIV/AIDS. The Lancet, 377, 2031-2041.

Smit, M., Brinkman, K., Geerlings, S., Smit, C., Thyagarajan, K., van Sighem, A., ... and Hallett, T. B. (2015). Future challenges for clinical care of an ageing population infected with HIV: a modelling study. The Lancet Infectious Diseases, 15, 810-818.

UNCTAD. (2013). World investment report. United Nations, New York and Geneva.

Siapka, M., Remme, M., Obure, C. D., Maier, C. B., Dehne, K. L., and Vassall, A. (2014). Is there scope for cost savings and efficiency gains in HIV services? A systematic review of the evidence from low-and middle-income countries. Bulletin of the World Health Organization, 92, 499511AD.

Sterck, O. (2016). Natural resources and the spread of HIV/AIDS: Curse or blessing? Social Science \& Medicine, 150, 271-278.

Sterck, O. (2017). What goes wrong with the allocation of domestic and international resources for HIV? Health Economics. 1-13.

Sterck, O., Roser, M., \& Thewissen, S. (2017). Turning the paradigm of aid allocation on its head (No. 2017-03). Centre for the Study of African Economies, University of Oxford.

UNAIDS (2014). 90-90-90 - An ambitious treatment target to help end the AIDS epidemic. Geneva: UNAIDS.

Walensky, R. P., Ross, E. L., Kumarasamy, N., Wood, R., Noubary, F., Paltiel, a D., Freedberg, K. a. (2013). Cost-effectiveness of HIV treatment as prevention in serodiscordant couples. The New England Journal of Medicine, 369, 1715-25.

World Health Organization (2013). Consolidated guidelines on the use of antiretroviral drugs for treating and preventing HIV infection. Geneva: World Health Organization.

Young, A. (2005). The gift of the dying: The tragedy of AIDS and the welfare of future African generations. The Quarterly Journal of Economics, 120, 423-466. 


\section{Appendix 1 - methodology for estimates}

\section{a) Assumptions}

The resources required for the moral duty to rescue were calculated assuming the following linear cost function:

$$
\text { Resources required }_{i j k}=\text { Reached population }_{i j k} \times{\text { Unit } \text { cost }_{i j k}}
$$

where $\mathrm{i}=$ country, $\mathrm{j}=\mathrm{year}, \mathrm{k}=$ service.

Our estimates are based on $81 \%$ coverage of ART at the $350 \mathrm{cells} / \mathrm{mm}^{3}$ eligibility threshold. Unit costs of treatment are presented in Table A1. They are assumed to be constant over time ${ }^{13}$ and are based on Schwartländer et al. (2011). Transition from 1st line to 2nd line ART was modelled assuming that $2.64 \%$ of people on treatment switch to $2^{\text {nd }}$ line therapy every year (Renaud-Théry et al., 2011). Testing costs and health care system are omitted, implying that the estimates presented in this section 2 are likely to underestimates the future cost of the moral duty to rescue.

Methodology using SPECTRUM

UNAIDS 2014 files for SPECTRUM were asked on http://apps.unaids.org/spectrum/ and downloaded for Kenya, Lesotho, Malawi, Uganda, Zimbabwe, Botswana, Nigeria and South Africa.

After opening the UNAIDS 2014 for a given country: 12 steps are needed to produce the estimates of section 3, Table 1:

1. The "Manager" is opened, the GOALS and RNM modules are selected and the timespan is extended to 2011-2050.

2. In GOALS, "configuration", the target year is set at 2050.

3. In GOALS, "coverage", prevention is set at 0 for all from 2015 for all interventions except circumcision (circumcision rates are in large part driven by other motives than HIV prevention and it is of course unrealistic to imagine that circumcised individuals would get uncircumcised).

4. In AIM, "program statistics", PMTCT is set at 0 from 2015 onwards.

5. In AIM, "program statistics", adult ART is set at $81 \%$ from 2015 onwards.

6. In AIM, "program statistics", child ART is set at $81 \%$ from 2015 onwards.

\footnotetext{
13 The literature is unclear how the unit cost of providing ART is likely to change as coverage is expanded. For a given level of health facilities unit costs can be expected to decrease as ART coverage is expanded, thanks to economies of scale and scope (e.g. Siapka et al. 2014). However, typically existing facilities only attract around half of the population, so that expanding coverage beyond this to 81 per cent of the eligible population is likely to incur additional cost of providing facilities for the hard-to-reach. Further, these costs are likely to increase over time as income rises. h and Over (2012), have shown that taking into account the need to expand health facilities implies a 42 per cent increase in the estimated cost of scaling up ART. The estimates we propose here are therefore likely to be lower bounds.
} 
7. In AIM, "eligibility for treatment", no population are set to be eligible for treatment regardless of CD4 count (all boxes are unchecked).

8. In AIM, "eligibility for treatment" is set at $350 \mathrm{CD} 4 / \mathrm{mm}^{3}$ or $500 \mathrm{CD} 4 / \mathrm{mm}^{3}$ depending on the scenario.

9. In RNM, "results", the "number of people reached summary" is copy pasted in an Excel spreadsheet.

10. In GOALS, "unit cost", all unit costs are set equal to 0 except from the cost of first line ARV and second line ARV which are set equal to 1 . This will allow us obtaining the number of adults on first and on second line therapy. The migration rate from first to second line therapy is set at $2.64 \%$ (Renaud-Théry et al., 2011).

11. In RNM, "results", "adult treatment costs", the summary of costs is copy-pasted into spread sheet. Given step 10, we can obtain the numbers on first line and second line ARV from this table. However, some precautions should be taken. First, it should be noted that the number on first line reported by RNM is in fact the total number of adults on ART (1st and 2nd line included). In order to obtain the real number of people on first line, on should take the number on first line reported by RNM minus the number on second line plus the number of children. The number of adults on second line is correctly reported by RNM.

12. The numbers of people on first and second line therapies are multiplied by the cost of ART in each country. These unit costs and their references are summarized in Table A1. Column (4) provides the result of this multiplication for the year 2015. For obtaining the numbers shown in column (6), we first discount and sum the costs of first line and second line therapies between 2015 and 2050. We then do a terminal value calculation in order to take into account the costs which are likely to occur after 2050. We divide the cost of the moral duty to rescue in 2050 by the discount rate to obtain the value of perpetuity. We discount this value of perpetuity and add the amount to the total discounted cost of the moral duty to rescue.

\begin{tabular}{lcccccccc}
\hline Services & $\begin{array}{c}\text { Botswana } \\
\text { UMIC }\end{array}$ & $\begin{array}{c}\text { Kenya } \\
\text { LIC }\end{array}$ & $\begin{array}{c}\text { Lesotho } \\
\text { Lower LMIC }\end{array}$ & $\begin{array}{c}\text { Malawi } \\
\text { LIC }\end{array}$ & $\begin{array}{c}\text { Nigeria } \\
\text { Lower LMIC }\end{array}$ & $\begin{array}{c}\text { South Africa } \\
\text { UMIC }\end{array}$ & $\begin{array}{c}\text { Uganda } \\
\text { LIC }\end{array}$ & $\begin{array}{c}\text { Zimbabwe } \\
\text { LIC }\end{array}$ \\
\hline \hline ART - first line & 704 & 343 & 430 & 343 & 430 & 704 & 343 & 343 \\
ART - second line & 2797 & 743 & 1157 & 743 & 1157 & 2797 & 743 & 743 \\
Circumcision & 64 & 64 & 64 & 64 & 64 & 64 & 64 & 64 \\
\hline
\end{tabular}

Table Al - unit costs per intervention (Source: Schwartländer et al., 2011) 
Four more steps are needed to obtain the estimates without incidence which are displayed in column (5) in Table 1. In particular, the four channels of transmission modeled in SPECTRUM should be set equal to zero from 2015 onwards.

1. Sexual transmission is set to 0 by setting the "Number of partners" to 0 in GOALS, "behavior".

2. Transmission for mother to child is set to 0 by setting abortion rate to 100 in AIM, "Program statistics".

3. The force of infection for IDU is set to 0 in GOALS, "Behavior".

4. The number of new infections due to blood transfusion is set to 0 in GOALS, "Epidemiology"

Then, the steps 11 and 12 are repeated to obtain estimates of the total cost of ART for this "noincidence" scenario. It is worth noting that this procedure could not be undertaken for Kenya. For unknown reasons, setting sexual transmission to 0 from 2015 onwards for Kenya also changes the incidence estimates before 2015, which is incoherent.

\section{Appendix 2 - Estimates using the 500 cells $/ \mathrm{mm}^{3}$ eligibility threshold}

\begin{tabular}{|c|c|c|c|c|c|c|}
\hline & $\begin{array}{c}(1) \\
\text { Adult } \\
\text { Prevalence } \\
2015 \\
\text { (spectrum) }\end{array}$ & $\begin{array}{l}\text { GDP per } \\
\text { capita }\end{array}$ & $\begin{array}{c}(3) \\
\text { External } \\
\text { debt } \\
\text { stock } \\
(2012)\end{array}$ & $\begin{array}{l}\text { Cost in } \\
2015\end{array}$ & \multicolumn{2}{|c|}{$\begin{array}{l}\text { Aggregated cost 2015- } \\
2050\end{array}$} \\
\hline & (\% adults) & $\begin{array}{r}(\$ \mathrm{US} \\
2015)\end{array}$ & $\% \mathrm{GNI}$ & $\%$ GDP & $\begin{array}{c}\text { No } \\
\text { incidence\% } \\
\text { GDP }\end{array}$ & $\begin{array}{c}\text { With } \\
\text { incidence\% } \\
\text { GDP }\end{array}$ \\
\hline Botswana & 21.6 & 8,332 & $18 \%$ & $1.11 \%$ & 21.0 & 28.8 \\
\hline Kenya & 3.7 & 1,588 & $31 \%$ & $0.34 \%$ & & 10.0 \\
\hline Lesotho & 13.9 & 1,390 & $31 \%$ & $2.45 \%$ & 41.8 & 93.3 \\
\hline Malawi & 8.0 & 275 & $32 \%$ & $3.84 \%$ & 59.7 & 92.2 \\
\hline Nigeria & 6.3 & 3,677 & $4 \%$ & $0.22 \%$ & 4.4 & 7.8 \\
\hline South Africa & 17.3 & 6,477 & $37 \%$ & $0.79 \%$ & 16.1 & 25.3 \\
\hline Uganda & 4.5 & 685 & $22 \%$ & $0.87 \%$ & 14.1 & 25.0 \\
\hline Zimbabwe & 13.4 & 1,073 & $76 \%$ & $2.10 \%$ & 35.7 & 46.8 \\
\hline
\end{tabular}

Sources: Column (1): adult prevalence in 2015 from SPECTRUM (Futures Institute, 2014).; Column (2): GDP per capita from IMF; Columns (3) to (6): authors' calculations

Table A2 - Replication of Table 1 considering the CD-4 count eligibility threshold of 500 cells $/ \mathrm{mm}^{3}$ - Financial Implications of Long-term ART: the Moral duty to rescue as a Quasi-Debt 